\title{
On the Potential of Urban Three-dimensional Space Development:
}

\section{The Case of Liuzhou, China}

\author{
Fangzhou Xia ${ }^{\mathrm{ab}}$, Yue Shen ${ }^{\mathrm{a}}$, Jinming Yan ${ }^{\mathrm{a}}$, Helen X. H. Bao ${ }^{\mathrm{b}^{*}}$ \\ ${ }^{a}$ Department of Land Management, School of Public Administration \& Policy, Renmin \\ University of China, Beijing, China \\ ${ }^{b}$ Department of Land Economy, University of Cambridge, Cambridge, UK
}

\begin{abstract}
:
The New-type Urbanization Plan in China is facing planning, economic, and environmental constraints. A fast-growing urban population imposes distinct pressure on social and natural resources in most cities. As a result, the urban land use pattern in China has rapidly expanded from planar to stereoscopic. Although the pattern has effectively maximized the utilization of land resources, the "one-size-fits-all" solution is not applicable to all cities in China. The assessment of the suitability of a city is important before the application of the "three-dimensional" (3D) development approach, especially for cities with important natural endowment at stake. This study proposes a framework to assess the potential of a city for 3D space development in China. Our model considers land use suitability, economic feasibility, and landscape visibility in urban 3D space development decisions. We use Liuzhou City as a case study to demonstrate the empirical implementation of this framework. Our analysis shows that the model can assist urban planners to visualize urban morphology and to identify optimal development directions. By balancing planning, economic, and environmental needs, our model enables local governments to meet their development targets without sacrificing the environment. The proposed framework is a useful tool for local government to realize the New-type Urbanization Plan while ensuring that urban residents "see the mountains, view the rivers, and remember their past."
\end{abstract}

Keywords: Three-dimensional space; Landscape view; Mixed model; New-type Urbanization

\footnotetext{
Corresponding author. Tel.: (44) 01223337 116; fax: (44) 01223337130.

E-mail addresses: ark_xiafangzhou@hotmail.com (Fangzhou Xia), shenyue_7@126.com (Yue Shen), yanjinming@mparuc.edu.cn (Jinming Yan), hxb20@cam.ac.uk (Helen X. H. Bao)
} 


\section{On the Potential of Urban Three-dimensional Space Development: The Case of Liuzhou, China}

\section{Introduction}

Higher levels of urbanization are associated with advanced economic development (Bertinelli \& Strobl, 2007; M. X. Chen, Zhang, Liu, \& Zhang, 2014). Moreover, rapid urbanization leads to various urban problems, such as congestion, crime, environmental externality, and housing affordability issues (See, for example, Burak, Dogan, \& Gazioglu, 2004; Deng, Huang, Rozelle, Zhang, \& Li, 2015; Glaeser, 2011; Voith \& Wachter, 2009). An estimated 66\% of the world's population will become urban by 2050 , and China plays a significant role in this process with its unprecedented urbanization speed (United Nations, 2014). Consequently, the demand for construction land for social and economic development has been increasing rapidly in China (Ding \& Lichtenberg, 2011; Gong, Chen, Liu, \& Wang, 2014). This demand has led to conflicts among sustainable development, environment protection, and economic growth, and to problems such as the disappearance of ecological land and the reduction of urban green space (Chen \& $\mathrm{Hu}$, 2015; Long, Liu, Hou, Li, \& Li, 2014).

In March 2014, China announced the "New-type Urbanization Plan" that calls for coordination among land urbanization, population growth, and environment protection (Xinhuanet, 2014). This plan indicates that the current land use pattern must be reviewed to reduce the waste of resources and to improve land use efficiency (Yan, Xia, \& Bao, 2015). Moreover, Chairman Jinping Xi stressed the importance of visible landscape in urban areas and demanded urban planners to ensure that residents can "see the mountains, view the rivers, and remember their past" (Taylor, 2015; Xinhuanet, 2013). In an effort to achieve these goals, many cities have opted to develop vertically into higher space and/or underground instead of sprawling out (Chen, Yan, Gao, \& Liu, 2015; Qin, Fang, Wang, Li, \& Wang, 2015; Shi \& Yang, 2015). This three-dimensional (3D) space development model has the benefits of promoting intensive and effective utilization of both overground and underground space (Wei, Huang, Lam, \& Yuan, 2015). The model is regarded as an important way to promote urban carrying capacity (Bendewald \& Zhai, 2013; Liu, 2012; S. Liu, Fan, Wen, Liang, \& Wu, 2014; Tian, Wu, \& Yang, 2010).

However, the 3D space development model is not a "one-size-fits-all" solution for all cities in China. The assessment of the suitability of a city for such an approach is important. In particular, cities with important natural endowment at stake should be carefully studied. This step can be done by evaluating the potential for 3D development at the city level. "Potential" refers to a currently unrealized ability or capacity by which an index may increase or reduce in a certain period or under a certain technical level (Krellenberg, Welz, \& Reyes-Packe, 2014). Therefore, we define urban 3D space potential as the capacity to increase available vertical space achieved through administrative, economic, legal, and technical measurements within planning and regulatory constraints in a certain period and at given technical levels (Joardar, 1998; Liu, 2012). Three aspects must be considered in estimating potential. First, the land must be suitable for 3D development construction (Zhang, Fang, Wang, \& Ma, 2013). Second, economic demand for 3D development should be present (Bendewald \& Zhai, 2013; Wei, et al., 2015; Wong, Tang, \& van Horen, 2006). Third, the utilization of the 3D space should not block the line-of-sight and result in 
landscape invisibility (Miller, 2001; Sander \& Manson, 2007). At the time of the writing of this study, the literature has focused on each of these three aspects. Other isolated efforts include studies on land use suitability evaluation (Gong, Liu, \& Chen, 2012; Wei, et al., 2015; Xu, Kong, Li, Zhang, \& Wu, 2011), economic demand analysis (Wragg \& Lim, 2015; Zacharias, 1999), and viewshed analysis (Llobera, 2003; Miller, 2001; Sander \& Manson, 2007; Wang, et al., 2015). Few researchers have conducted quantitative research on 3D urban morphology (see, e.g., Qin, et al., 2015), and most existing studies have focused on sub-regions of a city rather than the whole city area (see, e.g., Yoshida \& Omae, 2005; Yu, Liu, Wu, Hu, \& Zhang, 2010). Most importantly, no studies have investigated the potential for 3D space development by considering land use suitability, economic feasibility, and landscape visibility at the same time.

To bridge the gap in the literature, we develop a framework to assess the potential for 3D space development in urban China. Our model considers land use suitability, economic feasibility, and landscape visibility in urban 3D space development decisions. The framework consists of four steps. First, we divide a study area into evaluation units. Second, the land use suitability of these evaluation units is assessed to identify areas that are appropriate for construction. Third, the development potential (i.e., maximum development height for overground buildings and maximum development depth for underground constructions) of the identified evaluation units is determined through economic feasibility analysis. Finally, the overground development potential is adjusted to ensure landscape visibility. We use Liuzhou City as a case study to demonstrate the empirical implementation of this framework. Our analysis shows that the model can assist urban planners to visualize urban morphology and identify optimal development directions. By balancing planning, economic, and environmental needs, our model enables local governments to meet their development targets without sacrificing the environment. The proposed framework is a useful tool for local governments to realize the New-type Urbanization Plan while still ensuring urban residents that they will "see the mountains and water."

The rest of the study is structured as follows. Section 2 discusses the methodology and establishment of a digital three-dimensional space potential model (DTSPM). Taking Liuzhou City as a case study, Section 3 presents the details of the evaluation of land use suitability, economic feasibility, and landscape visibility. Section 4 presents and discusses the empirical findings. Section 5 provides the conclusion and policy implications.

\section{Methodology}

The composition of stakeholders and their alliances in the urbanization process could shift because the consensus on methods to utilize urban space varies over time (Jenkins-Smith \& Sabatier, 1994). Nevertheless, several stakeholder groups can still influence the direction of urban development by upholding values, such as livability, economic development, and environment protection (Berke \& Kaiser, 2006). Livability means that urban space development should support community activities, safety considerations, and preferred lifestyles. By meeting such a standard, developable land should be at least suitable for construction purposes. To deliver economic values, urban development and land use should generate profit from the sale of land and buildings. As a result, potential of urban space development is reflected by market demand (Logan \& Molotch, 
1987). Urban development should seek to protect urban environment for direct and indirect utility, as well as intrinsic values (Berke \& Kaiser, 2006). In the process of the New-type Urbanization in China, landscape visibility should be prioritized because the quality of view contributes significantly to the experiences of residents in the urban area (Bishop, Lange, \& Mahbubul, 2004; Guzey, 2014; Oh \& Lee, 2002; Rinner, 2007). The abovementioned values are integral to the quality living experience in urban China. Therefore, our research model is designed to recognize and reconcile land use suitability, economic feasibility, and landscape visibility in a unified framework. This goal is achieved by utilizing the digital elevation model (DEM) technique to develop the DTSPM outlined below.

DEM is a digital model that provides a 3D representation of a terrain that enables users to locate, visualize, and interpret vast amounts of geo-referenced information (F. Wang, et al., 2015). By using the data set of the plane coordinate $(X, Y)$ and height $(Z)$ of a regularly spaced grid, the spatial distribution of a topography can be described from a mathematical perspective (Sander \& Manson, 2007). DEM data can be converted into all types of thematic map productions, such as contour, slope, sectional drawing, hill shading, and landscape maps. DEM can also calculate volume, spatial distance, and coverage size of objects. This technique has been widely used in environmental studies (see, e.g., Daniels \& Lapping, 2005; Lindberg \& Grimmond, 2011; Stefanov, Ramsey, \& Christensen, 2001). By utilizing some carefully selected sample points, the model can appropriately interpolate and distribute discrete sample points to build a continuous 3D surface. Therefore, the technique enables us to utilize and consolidate a large amount of information effectively and efficiently. The technique is particularly useful in our research design, as our model inevitably needs to handle a wide range of indicators in considering livability, economic development, and landscape visibility at the same time. The technique also enables the 3D visualization of urbanization models of different specifications. The friendly interface is particularly useful for policy makers and the public that do not necessarily have special knowledge in areas, such as geology and construction.

We build the DTSPM by applying the DEM principle. As shown in Figure 1, the model considers the preconditions of sustainable urban development, such as livability, economic feasibility, and ecology from a top-down perspective (van Lier, 1998). Through the evaluation of land use, economic feasibility, and landscape visibility, the model is capable of incorporating local particulars. Therefore, the model is regarded as an intermediate toward the bottom-up approaches. DTSPM can visualize any specific New-type Urbanization form, as the model can illustrate 3D space potential at any spatial position of a city or a region. The model provides insights into whether a city or a region is suitable for $3 \mathrm{D}$ development in terms of livability, economic development, and landscape visibility. In the following section, we use Liuzhou City to demonstrate the implementation of DTSPM in a four-step procedure. 


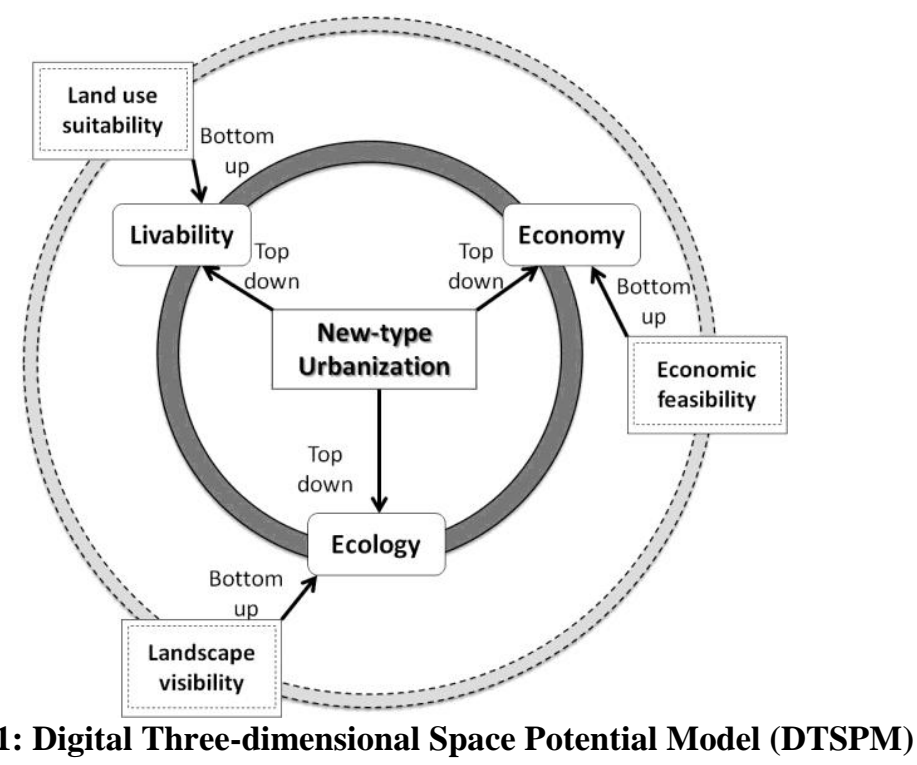

Figure 1: Digital Three-dimensional Space Potential Model (DTSPM)

\section{Empirical Implementation}

\subsection{Study Area and Data Resource}

The study area is Liuzhou, which is located in the north of Guangxi Province, China (see Figure 2). As the second largest city in Guangxi Province, Liuzhou is an industrial hub in Southwest China and a core city in the Xijiang Economic Belt. The city is widely known for having the most beautiful landscape among major industrial cities in China. The total land area of the city is 18,686 square kilometers, including four districts and six counties. The four districts, namely, Chengzhong, Yufeng, Liunan, and Liubei, form the central urban area of Liuzhou. In 2012, the gross domestic product (GDP) of the four districts combined reached 132 billion RMB, which accounted for $72.71 \%$ of the whole city's GDP. The central urban area hosts a population of 1.5585 million, which comprises $40.75 \%$ of the whole city. Therefore, the per capita GDP and population density are higher in this "urban core" than the average level of Liuzhou. In 2012, the green space ratio in the central urban area was $45.7 \%$, and the rate of good air quality was $96.2 \%$, which translates into 352 days with good air quality per year. This achievement is impressive given the fact that Liuzhou is an industrial city. In addition, the geomorphology of the central urban area is a typical Karst landform, which is surrounded by mountains with a beautiful landscape. Moreover, Liujiang River runs across the city and encircles the area as a "U" glyph peninsula. On the one hand, Liuzhou is endowed with natural resources to support a desirable living environment. On the other hand, the city is facing great challenges in preserving these natural endowments while implementing the New-type Urbanization Plan. For this reason, we choose Liuzhou as the study area to demonstrate that our DTSPM can assist planners to strike a balance between urban development and sustainability.

The data are collected from survey databases, statistical yearbooks , and bulletins provided by the Liuzhou Bureau of Land and Resources and Housing Management. Specifically, geological factors and hazard risk measurements come from the National Second Land Use Survey database. Hydrographic factors are taken from the Water Resource Bulletin of Liuzhou City (2013); climatic 
factors are retrieved from the Environmental Quality Monitoring Report of Liuzhou City (2013); planning factors are collected from the Land Use Planning of Liuzhou City (2005-2020); economic demand factors are from the statistical yearbooks of Liuzhou City (2013); and limit correction factors are obtained from the Urban Planning of Liuzhou City (2010-2020).

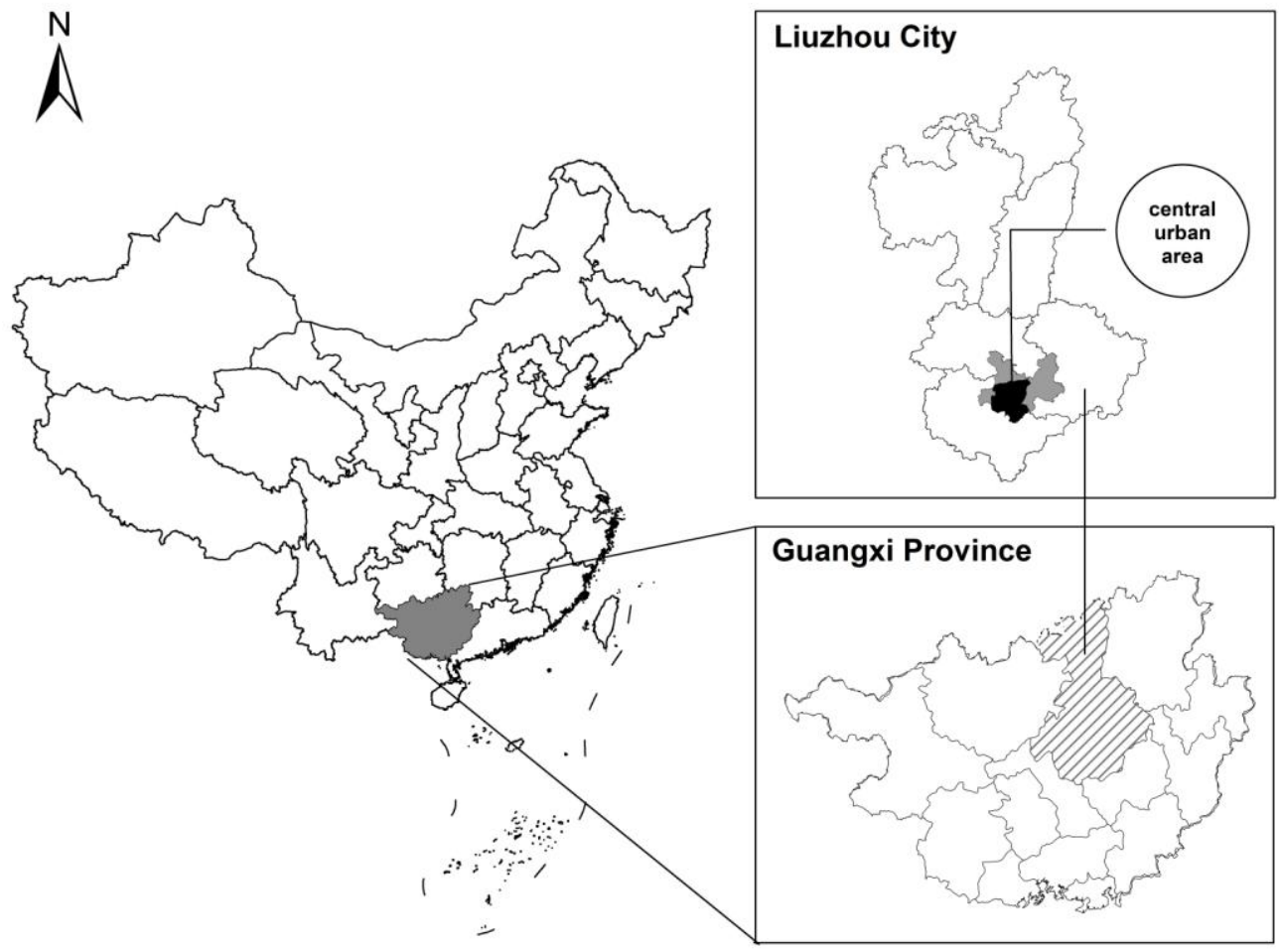

Figure 2: Location of Liuzhou City

\subsection{Steps of DTSPM}

\section{Step 1: Determine Evaluation Units}

Evaluation units are the base units from which information is collected and through which the analysis of land use suitability, economic feasibility, and landscape visibility is carried out. The results are then combined to form a complete picture of the 3D development potential for the whole study area. The size of the evaluation units determines the level of aggregation of the analysis. In this sense, evaluation units can be viewed as the pixels that determine the resolution of the big picture. For example, a DTSPM that uses street blocks as evaluation units can assess the 3D space development potential at the street, district, city, or even regional level. This feature offers great flexibility to planners who can "zoom in" or "zoom out" to retrieve information at a desirable aggregation level. However, if available data are limited to the city level, street or district level analysis will not be possible.

The size of evaluation units is largely determined by data availability and computational cost. The DTSPM model needs inputs about geological, economic, social, and geographical characteristics of the evaluation units. The information is then translated into a large amount of data to process. Choosing smaller evaluation units may raise the cost of data collection and 
computation time substantially. However, an analysis using large evaluation units may not produce meaningful results. Therefore, a delicate balance is essential. In the case of Liuzhou City, detailed data are available. Using a comprehensive geo-coded database, we divide the whole city into over 20,000 crustal blocks. We then adjust the boundary by considering natural and administrative divisions, such as streets and rivers. Finally, we obtain 13,400 crustal blocks that are used as evaluation units in our DTSPM analysis.

\section{Step 2: Evaluate Land Use Suitability}

To determine whether a land parcel is suitable for construction, we consider factors that have been widely used in the literature for similar purposes. These factors include topography, water, geological hazard risk, and protected areas (Dai, Lee, \& Zhang, 2001; Zhang, et al., 2013). Using these indicators, we develop an index system to assess the land use suitability of Liuzhou City. In total, we consider four factors (i.e., geologic, geological hazard risks, hydrographic, and planning factors) and seven indicators, as shown in Table 1. Based on the value of these indicators, the index system classifies the evaluation units into two groups, namely, suitable (S) and not suitable (N). The threshold values of our index system are adopted from Wang, $\mathrm{Xu}$, and $\mathrm{Xu}(2005)$ and $\mathrm{Xu}$, et al. (2011). A minimum threshold method is used to classify the land areas as suitable for 3D space development or not (Xia, Xia, \& Yan, 2011; Zhang, et al., 2013). Specifically, an evaluation unit needs to meet the minimum threshold requirements in all factors to be classified as "suitable" overall.

Table1: Threshold Values of Land Use Suitability Evaluation

\begin{tabular}{|c|c|c|c|c|}
\hline Factors & Indicators & Unit & Suitable (S) & Not Suitable (N) \\
\hline \multirow[b]{2}{*}{ Geological } & Slope & Degree & $0-15$ & $>15$ \\
\hline & $\begin{array}{l}\text { Ground bearing } \\
\text { capacity }\end{array}$ & $\mathrm{kPa}$ & $\leq 600$ & $>600$ \\
\hline $\begin{array}{c}\text { Geological } \\
\text { hazard risks }\end{array}$ & $\begin{array}{l}\text { Possibility of } \\
\text { geographic hazard } \\
\text { such as gully, hill } \\
\text { creep, subsidence }\end{array}$ & N/A & $\begin{array}{c}\text { None or } \\
\text { secondary } \\
\text { geological } \\
\text { hazard }\end{array}$ & $\begin{array}{c}\text { Tertiary or } \\
\text { devastating } \\
\text { geological hazard } \\
\text { area }\end{array}$ \\
\hline \multirow[b]{2}{*}{ Hydrographic } & Groundwater table & Meter & $\leq 6$ & $>6$ \\
\hline & Water supply & N/A & $\begin{array}{l}\text { Availability of } \\
\text { running, ground, } \\
\text { or river water }\end{array}$ & $\begin{array}{l}\text { Difficult supply } \\
\text { water }\end{array}$ \\
\hline \multirow[t]{2}{*}{ Planning } & $\begin{array}{l}\text { Use control - } \\
\text { overground }\end{array}$ & N/A & $\begin{array}{l}\text { Unrestricted or } \\
\text { construction } \\
\text { land, or need } \\
\text { acquisition or } \\
\text { diversion } \\
\end{array}$ & $\begin{array}{l}\text { Plough, } \\
\text { transportation land, } \\
\text { green area, or other } \\
\text { ecological land }\end{array}$ \\
\hline & $\begin{array}{l}\text { Use control - } \\
\text { underground }\end{array}$ & N/A & $\begin{array}{l}\text { Unrestricted or } \\
\text { ecological land, } \\
\text { e.g., green area }\end{array}$ & $\begin{array}{l}\text { Underground use } \\
\text { forbidden by } \\
\text { planning }\end{array}$ \\
\hline
\end{tabular}




\section{Step 3: Analyze Economic Feasibility}

Aside from economic features of the study region, the economic analysis of urban expansion involves other factors such as infrastructure and social traits ( $\mathrm{Li}$, Sato, \& Zhu, 2003). As space demand by urban residents is a main driver of urban expansion, demographic indicators such as population size or density are potential determinants of land use patterns (Pacione, 2001; Turner II, et al., 1995). In the literature, researchers consider the size of both permanent population (i.e., registered population) and temporary population (i.e., floating population). As statistics on temporary population is of poor quality in China, we opt to use registered population size only. We do not consider population density because our evaluation units are of similar size. Therefore, population density is highly correlated with population size.

Our survey of the literature reveals a wide range of economic indicators to be considered in this evaluation. First, the benchmark or average land price consists of a large proportion of development cost, and it consequently affects the economic values of urban development significantly (Ding, 2001; Ding \& Lichtenberg, 2011). Second, planning controls and regulations, such as density of business service center, plot ratio, volumetric fraction, and development density, are significant determinants of development cost, real estate price, and ultimately, profitability of development projects (Chau \& Wong, 2014; Ding, 2003; Jou \& Lee, 2015). Therefore, we include all these indicators in our model.

The quality and scope of infrastructure of a city can affect development values as well (Cho, 2011; Ding, 1996). For example, indicators such as road network density, distance to CBD, and infrastructure completion degree, among others, can significantly influence the demand for urban space. These factors are routinely included in economic feasibility studies on urban development (See, for example, Garcia-Lopez, 2012; Yang, Zhu, \& Moodie, 2015). In the context of Liuzhou City, we use road network density in our model.

On the basis of our review of the literature and considering the local particulars of Liuzhou City, we select 10 indicators to assess the economic feasibility of urban development for each evaluation unit. For each unit, the value of each indicator is normalized to remove scaling issues. Specifically, we let $X(i, j)$ be the $j$ th indicator of the $i$ th evaluation unit. The normalized indicator $X^{*}(i, j)$ is calculated using Equation (1).

$$
X^{*}(i, j)=\frac{X(i, j)-X_{\min }(j)}{X_{\max }(j)-X_{\min }(j)},
$$

where $X_{\max }(j)$ and $X_{\min }(j)$ are the maximum and minimum values, respectively, of indicator $j$ among all evaluation units. $X^{*}(i, j)$ is constructed to take values within $[0,1]$ only.

After obtaining the normalized values of each indictor, the overall economic feasibility score, $C_{i}$, can be calculated using the following formula:

$$
C_{i}=\sum_{j=1}^{10} X^{*}(i, j) \times w_{j} .
$$


In Equation (2), $C_{i}$ is a comprehensive score that measures the 3D space development potential of the evaluation unit $i . w_{j}$ is the weight of the $j$ th indicator, which is calculated using an analytic hierarchy process (the values are given in the last column in Table 2$)^{1} . X^{*}(i, j)$ has been defined previously.

Considering both land use and economic feasibility for 3D development, the maximum development height/depth of unit $i$ can be calculated as

$$
H_{\max , i}=C_{i} \times H_{\max },
$$

where $H_{\max }$ is the maximum building height/underground-depth in the region. $H_{\max , i}$ is determined by meeting the construction and economic requirements only. Landscape visibility is not considered in the calculation. This equation is adjusted accordingly in the next step through viewshed analysis.

Table 2: Economic Feasibility of the Analysis Indicators

\begin{tabular}{l|l|c}
\hline \multicolumn{1}{c|}{ Factors } & \multicolumn{1}{c|}{ Indicators } & Weight $\left(w_{j}\right)$ \\
\hline Demographic & Registered population & 0.12 \\
\hline \multirow{5}{*}{ Economic } & Density of the business service center & 0.12 \\
\cline { 2 - 3 } & Benchmark land price (Residential) & 0.07 \\
\cline { 2 - 3 } & Benchmark land price (Commercial) & 0.11 \\
\cline { 2 - 3 } & Average land price (Residential) & 0.09 \\
\cline { 2 - 3 } & Average land price (Commercial) & 0.12 \\
\cline { 2 - 3 } & Plot ratio & 0.08 \\
\cline { 2 - 3 } & Building volumetric fraction & 0.09 \\
\cline { 2 - 3 } & Site construction density & 0.10 \\
\hline Infrastructure & Road network density & 0.10 \\
\hline
\end{tabular}

\section{Step 4: Analyze Landscape Visibility}

Landscape visibility analysis is conducted through viewshed analysis, which is widely used in the 3D Digital Earth System and has a wide range of applications (Defloriani, Marzano, \& Puppo, 1994; Sander \& Manson, 2007). This step aims to ensure the visibility of the landscape, especially the mountains and rivers. In the context of the New-type Urbanization Plan of China, the objective is to preserve desirable views while enabling the construction of high-rise buildings. By choosing measurements, such as viewshed width, sight corridors, and sight range, the possible adverse effects of 3D space development can be alleviated (Bishop, Wherrett, \& Miller, 2000; Turner, Doxa, O'Sullivan, \& Penn, 2001).

In the previous step, the maximum development high for each evaluation unit is determined

\footnotetext{
1 The procedure was used in Xu et al. (2011). For simplicity, we report the results of $w_{j}$ in Table 2 only. Further details of the calculations are available from the authors upon request.
} 
on the basis of the analysis of both construction potential and economic values. In this final step of DTSPM, we construct a digital surface to create the contour of distribution and a 3D design sketch of the 3D space potential through ArcGIS and SketchUp. Then, by overlaying remote sensing images, we impose rules and constraints to modify the maximum development height to achieve the desirable viewshed. The procedure, which has been widely used in the literature (see, e.g., Koltsova, Tuncer, \& Schmitt, 2013; X. Yang \& Li, 2013; Zacharias, 1999), is outlined below.

The analysis starts from identifying scenic spots, e.g., a beautiful mountain, a large park, or a large body of water. Next, sites from which scenic spots should be visible are chosen as viewpoints. The viewshed procedure computes locations that are connected by a line-of-sight between a viewpoint and a scenic spot within a specified distance in an elevation model (De Floriani \& Magillo, 2003; Defloriani, et al., 1994). To achieve a barrier-free visual communication between a viewpoint and a scenic spot, we need to construct a corridor of sight line with no buildings that are higher than the viewshed requirements between the scenic spot and the viewpoint. The corridor of sight line can be identified by two measurements, namely, viewshed length and viewshed width (Sander \& Manson, 2007). Viewshed length is the distance of a view corridor between a viewpoint and a scenic spot, and it makes up the sight line to determine the visibility of mountains. Viewshed width is the angle of artificial open space, such as the angle of the corridor of sight line constituted by streets, plazas, and landscape elements, such as a river. As shown in Figure 3, in the red triangle area, vertical development should not surpass the top red line of the corridor of sight line so that the view of the mountain is unobstructed. This feature is largely determined by the distance between a viewpoint and a scenic spot, i.e., the viewshed length. Similarly, in the green triangle area, the layout of 3D space needs to ensure the viewshed width to guarantee that the neighboring buildings will not block the view of the river. The effect is more visible in Figure 4, where the height of Building $\mathrm{A}$ is reduced to meet the viewshed length constraints, while Building $\mathrm{B}$ is shortened or removed to meet the viewshed width requirements.

In the context of Liuzhou City, we use a viewshed width of $500 \mathrm{~m}$ in our analysis. The value of the viewshed length is determined by the distance between specific viewpoints and scenic spots. On the basis of the rules of viewshed length and width, we modify the building height for each viewpoint using the 3D design sketch to make the mountain and the river visible. With these four steps, we can finally determine and visualize the potential of 3D development for Liuzhou City. 


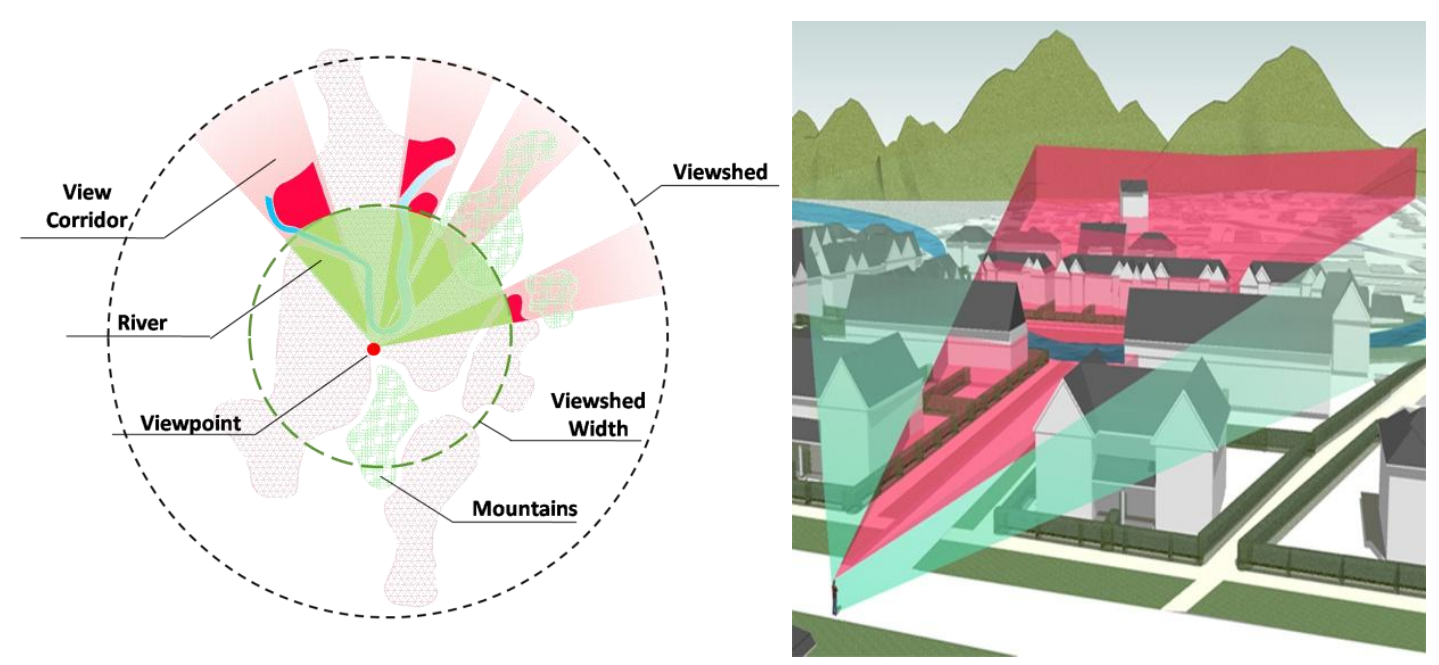

Figure 3: Viewshed Analysis (Aerial View)

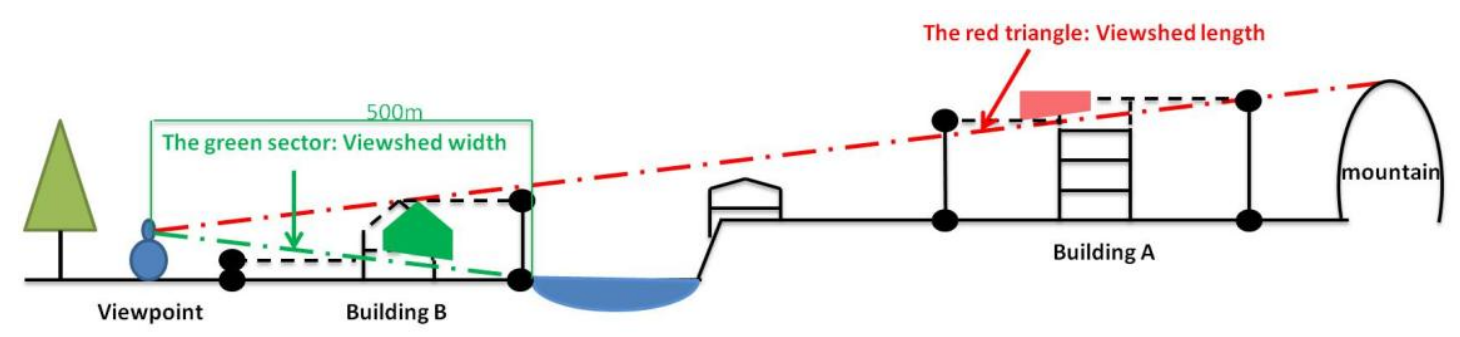

Figure 4: Viewshed Analysis (Cross-sectional View)

\section{Empirical Results and Discussions}

\subsection{Evaluation of Land Use Suitability}

As given in Figure 5, we divide the land suitability of Liuzhou City for 3D space development into two groups, namely, suitable (S) and not suitable (N). Liunan District has the largest area of suitable land for 3D space development, i.e., 5486.43 ha. Liubei District has a total of 4464.69 ha of land area suitable for 3D development, followed by Yufeng District with 3058.77 ha and Chengzhong District with 1533.26 ha. In terms of sub-districts, Taiyangcun Sub-district has the largest area of suitable land for 3D space development, i.e., $1825.86 \mathrm{ha}$, followed by Yanghe Sub-district with 1496.93 ha. The areas suitable for 3D development are the smallest in Wulihe, Tianma, and Chengzhong Sub-districts, which have 21.64, 31.82, and 60.91 ha, respectively.

The results of the land use suitability analysis are reported in the first column of Table 3 . Given the large number of evaluation units used in our model, we give summary statistics by district instead of by evaluation unit. We calculate the statistics in Table 3 by averaging the corresponding figures from all evaluation units in each district/sub-district. In the next step, only evaluation units identified as "suitable" are used. This result restricts our analysis to 1,613 evaluation units only. 


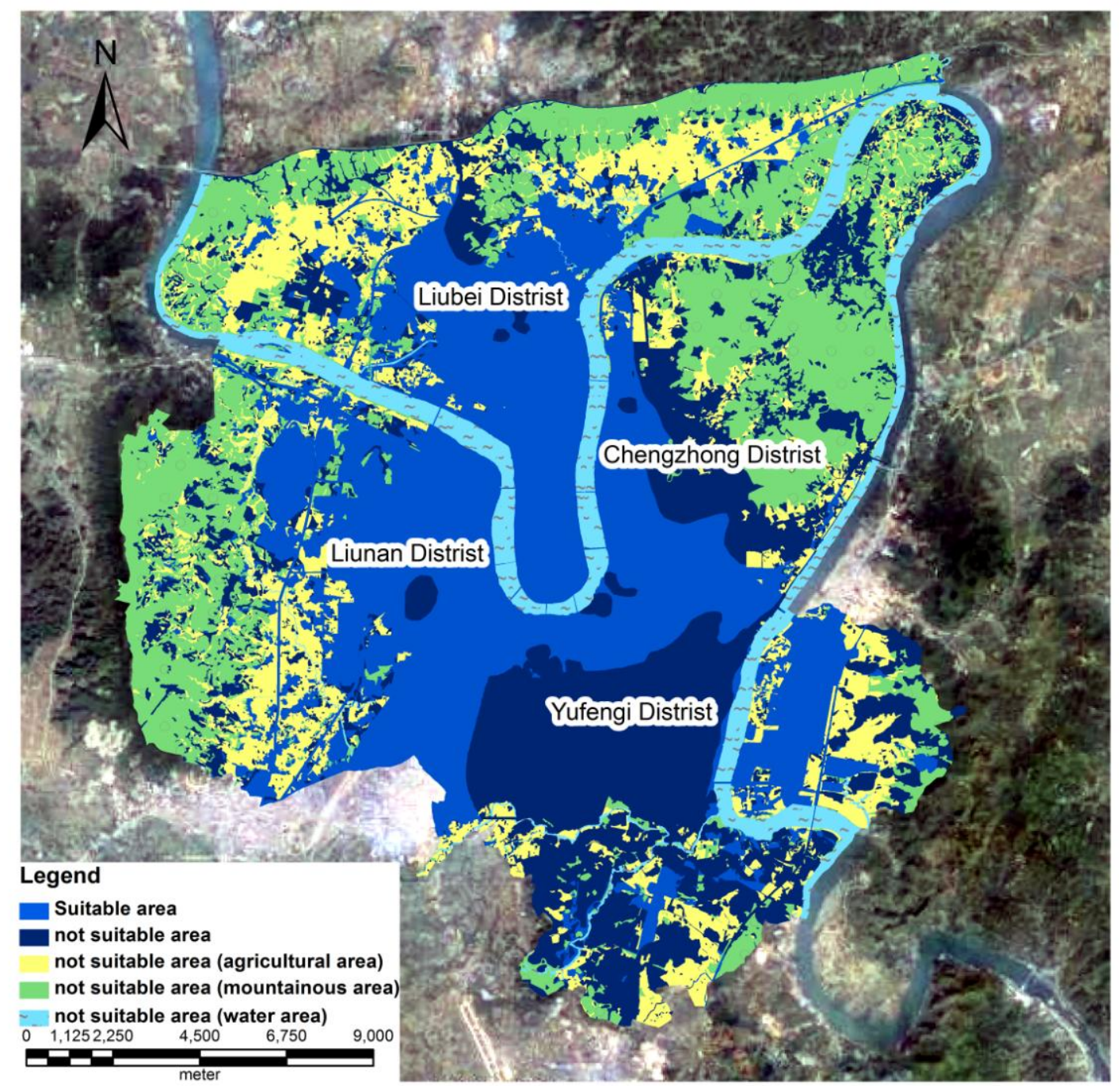

Figure 5 Results of the Evaluation of Land Use Suitability (Liuzhou, China)

\subsection{Economic Feasibility Analysis}

The highest building in Liuzhou City is the so-called "Land King Building." The name comes from the fact that the developer acquired the land parcel at a record high price. This property is considered the landmark building of the city and is still under construction at the time of writing of this study. Therefore, we use the height of "Land King Building," which is $300 \mathrm{~m}$, as the maximum building height in the study area. According to planning regulations in Liuzhou, the maximum underground development depth is $40 \mathrm{~m}$. We use Equation 2 to measure the potential of 3D space development of all evaluation units selected in Step 2. The results are reported in Table 3. In comparison, Yufeng District has the lowest development potential, as reflected by the low comprehensive index number and the maximum development height/depth on average. Chengzhong District has the highest development potential. Figures 6 and 7 (generated by ArcGIS) show that the 3D development potential could vary within a small geographic area. Our model is flexible enough to capture and reflect the local heterogeneity when determining the development potential for both overground and underground projects. Nevertheless, whether the estimated potential can be fully realized after considering the environmental factors depends on the results of the viewshed analysis. 
Table 3: Results of the Economic Feasibility Analysis

\begin{tabular}{|c|c|c|c|c|}
\hline \multirow[t]{2}{*}{ Name } & \multirow{2}{*}{$\begin{array}{l}\text { Suitable Area for } \\
\text { 3D Space } \\
\text { Development }\left(\mathrm{m}^{2}\right)\end{array}$} & \multirow{2}{*}{$\begin{array}{c}\text { Comprehensive } \\
\text { Index } \\
C_{i} \\
\end{array}$} & \multicolumn{2}{|c|}{$\begin{array}{l}\text { Development Potential (meter) } \\
\qquad H_{\max , i}\end{array}$} \\
\hline & & & Overground & Underground \\
\hline Chengzhong District & Total: 1533.26 & Average: 0.58 & Average: 175.11 & Average: 23.35 \\
\hline Chengzhong Sub-district & 60.91 & 0.99 & 295.86 & 39.45 \\
\hline Gongyuan Sub-district & 88.85 & 0.58 & 173.22 & 23.10 \\
\hline Zhongnan Sub-district & 72.38 & 0.69 & 208.44 & 27.79 \\
\hline Tanzhong Sub-district & 642.75 & 0.54 & 162.03 & 21.60 \\
\hline Hedong Sub-district & 411.33 & 0.40 & 121.44 & 16.19 \\
\hline Jinglan Sub-district & 257.04 & 0.30 & 89.67 & 11.96 \\
\hline$\underline{\text { Yufeng District }}$ & Total: $\mathbf{3 0 5 8 . 7 7}$ & Average: 0.47 & Average: 140.23 & Average: 17.45 \\
\hline Tianma Sub-district & 31.82 & 0.42 & 127.02 & 16.94 \\
\hline Jiahe Sub-district & 127.19 & 0.59 & 175.50 & 23.40 \\
\hline Jianpan Sub-district & 287.97 & 0.52 & 157.05 & 20.94 \\
\hline Wuliting Sub-district & 21.64 & 0.42 & 125.46 & 16.73 \\
\hline Longjun Sub-district & 230.13 & 0.53 & 157.83 & 21.04 \\
\hline Bailian Sub-district & 324.12 & 0.33 & 98.52 & 13.14 \\
\hline Qilin Sub-district & 538.97 & 0.43 & 128.85 & 17.18 \\
\hline Yanghe Sub-district & 1496.93 & 0.26 & 76.83 & 10.24 \\
\hline$\underline{\text { Liunan District }}$ & Total: $\mathbf{5 4 8 6 . 4 3}$ & Average: 0.52 & Average: 157.11 & Average: 17.69 \\
\hline Hexi Sub-district & 818.44 & 0.44 & 131.88 & 17.58 \\
\hline Nanzhan Sub-district & 363.52 & 0.42 & 126.60 & 16.88 \\
\hline Eshan Sub-district & 470.54 & 0.41 & 123.75 & 16.50 \\
\hline Liunan Sub-district & 134.85 & 0.77 & 231.21 & 30.83 \\
\hline Liushi Sub-district & 167.36 & 0.59 & 177.99 & 23.73 \\
\hline Yinshan Sub-district & 390.30 & 0.50 & 151.20 & 20.16 \\
\hline Tanxi Sub-district & 667.65 & 0.31 & 91.65 & 12.22 \\
\hline Nanhuan Sub-district & 647.90 & 0.42 & 126.33 & 16.84 \\
\hline Taiyang Sub-district & 1825.86 & 0.11 & 33.66 & 4.49 \\
\hline$\underline{\text { Liubei District }}$ & $\underline{\text { Total: } \mathbf{4 4 6 4 . 6 9}}$ & Average: 0.49 & Average: 146.23 & Average: 17.43 \\
\hline Jiefang Sub-district & 228.21 & 0.75 & 225.60 & 30.08 \\
\hline Yalu Sub-district & 792.54 & 0.67 & 201.45 & 26.86 \\
\hline Shengli Sub-district & 516.28 & 0.40 & 118.98 & 15.86 \\
\hline Queershan Sub-district & 501.55 & 0.31 & 94.26 & 12.57 \\
\hline Gangcheng Sub-district & 582.29 & 0.33 & 100.20 & 13.36 \\
\hline Jingxiu Sub-district & 302.21 & 0.46 & 136.86 & 18.25 \\
\hline Bailu Sub-district & 813.57 & 0.21 & 62.40 & 8.32 \\
\hline Liuchang Sub-district & 728.05 & 0.35 & 106.26 & 14.17 \\
\hline
\end{tabular}




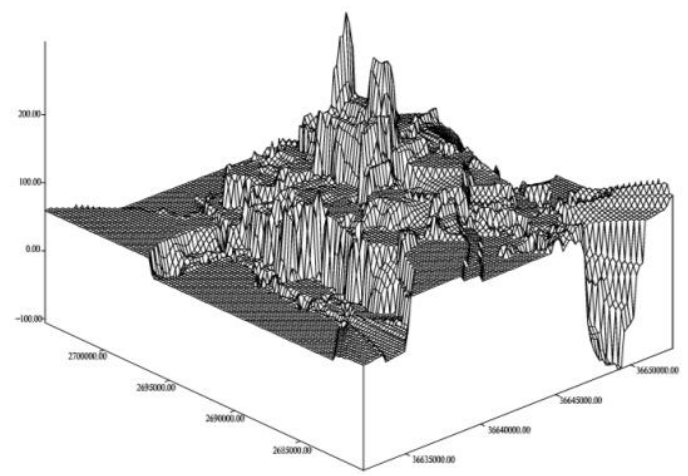

Figure 6: Overground Development Potential

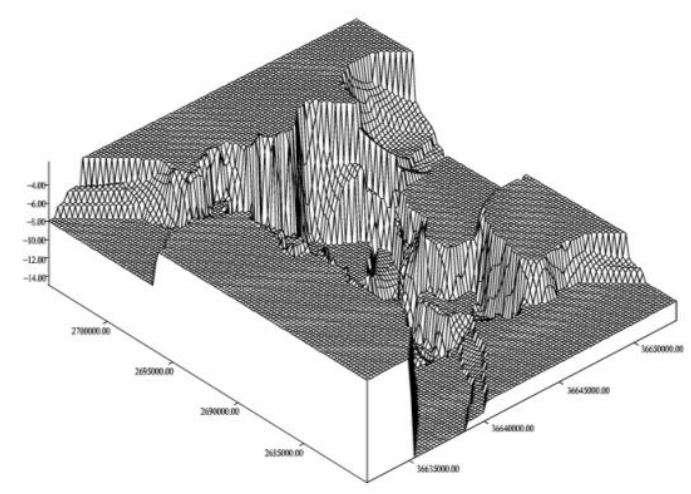

Figure 7: Underground Development Potential

\subsection{Landscape Visibility Analysis}

Liuzhou City provides a unique setting to test our model. The city is surrounded by Liujiang River and several mountains. The area has the river running across and mountains are located in the heart of the city. The city, the river, and several mountains in and around the city are closely knitted together (See Figure 8). As a result, the landscape poses challenges and opportunities to meet the "see the mountains and water" requirement. Without losing generality, we randomly select 100 viewpoints from the central area of the city and 50 viewpoints within $500 \mathrm{~m}$ along the Liujiang River. The locations of these viewpoints are indicated in Figure 8 using red dots ${ }^{2}$. With Liujiang River and the mountains as scenic spots, we construct the viewshed corridor between every viewpoint and its target scenic spots (i.e., nearest mountain or water). We apply the rules as described in previous sessions to remove the negative effect of vertical space development. For illustration purposes, the revised 3D development potential is reported for the seven randomly selected evaluation units from Chengzhong District in Table 4. Taking evaluation unit No.503495 as an example, the original maximum development height (i.e., $127 \mathrm{~m}$ ) obstructs the view of the mountains. To increase the visibility of the mountains, the maximum development height should be reduced from $127 \mathrm{~m}$ to $87 \mathrm{~m}$. However, the adjustment is not uniform. The notable variation in height adjustment within a small geographic region is a result of the careful consideration of the local landscape resources and constraints. Therefore, a balance between local and global optimal in the urban development design can be achieved. This example demonstrates the flexibility of our DTSPM framework.

\footnotetext{
${ }^{2}$ We adopt this approach for demonstration purposes. Including all the possible viewpoints makes the visualization of the results difficult.
} 


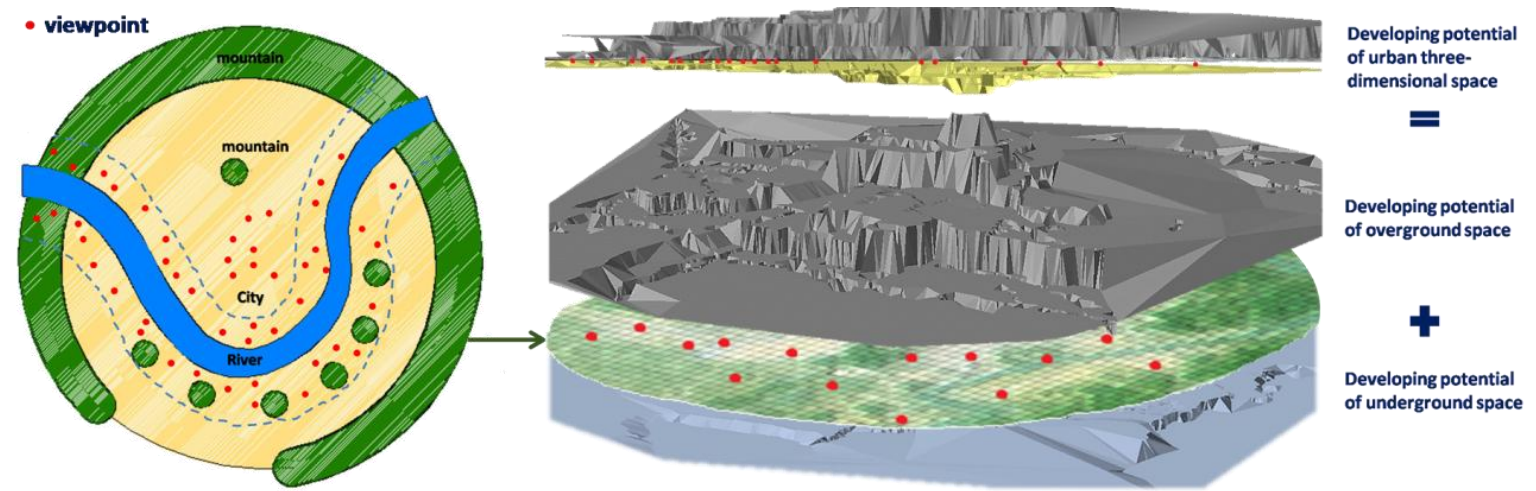

Figure 8: Distribution of Viewpoints and Scenic Spots in Liuzhou

Table 4: Modification Results of the Over-ground Potential after Viewshed Analysis

\begin{tabular}{c|c|c|c}
\hline $\begin{array}{c}\text { Evaluation Unit } \\
\text { Number }\end{array}$ & $\begin{array}{c}\text { Maximum Development } \\
\text { Height - before } \\
(\mathbf{m})\end{array}$ & $\begin{array}{c}\text { Maximum Development } \\
\text { Height - after } \\
(\mathbf{m})\end{array}$ & $\begin{array}{c}\text { Adjustment } \\
(\mathbf{m})\end{array}$ \\
\hline 503495 & 127 & 87 & -40 \\
\hline 504443 & 164 & 121 & -43 \\
\hline 504447 & 90 & 69 & -21 \\
\hline 504454 & 90 & 68 & -22 \\
\hline 504458 & 164 & 141 & -23 \\
\hline 504724 & 90 & 79 & -11 \\
\hline 504725 & 90 & 73 & -17 \\
\hline
\end{tabular}

To illustrate the full effect of the viewshed analysis on the city landscape as a whole, we calculate a landscape visibility rate (LVR) for both mountain and river views. Once a sight line is established, the viewshed analysis improves the scenic visibility for the viewpoint itself and the views for all the evaluation units along the sight line. LVR is the proportion of evaluation units with mountain or river views among all evaluation units considered in a given area. After implementing the adjustment suggested by viewshed analysis, $13.27 \%$ improvement of LVR is determined in all affected areas of chosen viewpoints (Table 5). In general, increasing the number of viewpoints further improves LVR.

Figure 9 shows the final stage of our analysis, i.e., a 3D realization of the final results of our DTSPM model. This output can serve as a blueprint of Liuzhou City to support the important and challenging decisions to be made by urban planners. However, Figure 9 is not a standard blueprint that mainly considers geological information and construction requirements. Both economic and environmental elements are embedded in the sketch. By referencing building height and location as suggested in Figure 9, planners can implement the New-type Urbanization Plan without sacrificing environmental amenities. 
Table 5: Landscape Visibility Rate Analysis

\begin{tabular}{|c|c|c|c|c|c|c|c|c|}
\hline \multirow[b]{2}{*}{ District } & \multirow{2}{*}{$\begin{array}{l}\text { Total } \\
\text { Area } \\
\text { (ha) }\end{array}$} & \multirow{2}{*}{$\begin{array}{c}\text { Affected } \\
\text { Area } \\
\text { (ha) }\end{array}$} & \multicolumn{3}{|c|}{ Viewpoint Counts } & \multicolumn{3}{|c|}{ LVR Improvement (\%) } \\
\hline & & & $\begin{array}{l}\text { Viewshed } \\
\text { Length }\end{array}$ & $\begin{array}{c}\text { Viewshed } \\
\text { Width }\end{array}$ & Total & $\begin{array}{c}\text { Mountain } \\
\text { View }\end{array}$ & $\begin{array}{l}\text { Water } \\
\text { View }\end{array}$ & $\begin{array}{c}\text { Total } \\
\text { Improvement }\end{array}$ \\
\hline Chengzhong & 7760.32 & 842.17 & 14 & 11 & 25 & 4.41 & 6.44 & 10.85 \\
\hline Liubei & 10625.6 & 1543.74 & 14 & 21 & 35 & 8.55 & 5.98 & 14.53 \\
\hline Liunan & 10516.99 & 2115.24 & 44 & 16 & 60 & 16.18 & 3.94 & 20.11 \\
\hline Yufeng & 9225.76 & 560.04 & 28 & 2 & 30 & 5.82 & 0.25 & 6.07 \\
\hline Total & 38128.67 & 5061.19 & 100 & 50 & 150 & 9.15 & 4.12 & 13.27 \\
\hline
\end{tabular}

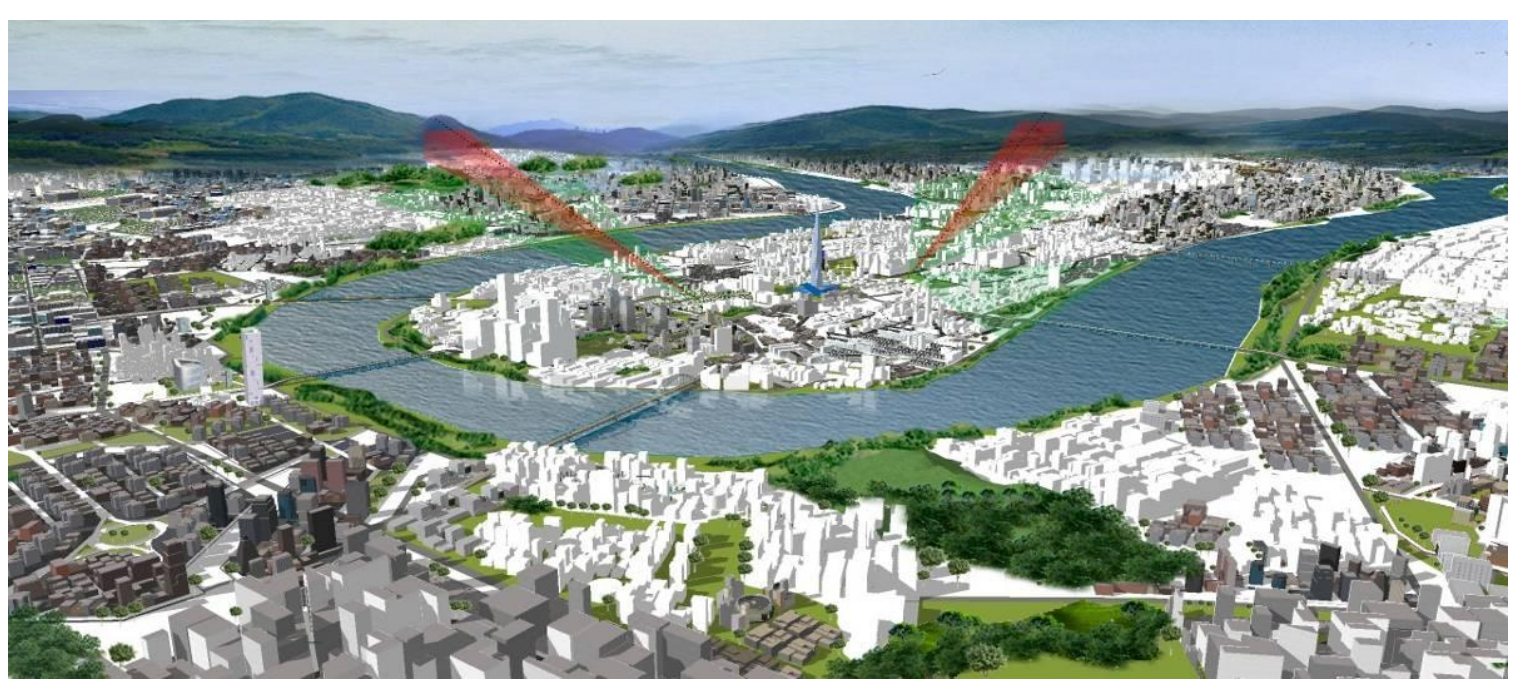

Figure 9: 3D Design Sketch of the Urban Morphology of Liuzhou

\section{Conclusion}

Given the sheer population size and limited land supply of China, 3D urban development has gained popularity among Chinese cities. Although this development model effectively improves the urban carrying capacity by increasing building height, the model poses challenges to an important requirement of the New-type Urbanization Plan. This requirement should ensure that residents can "see the mountains, view the rivers, and remember their past." To address this issue, we propose the DTSPM that analyzes land use suitability, economic feasibility, and landscape visibility in a unified framework. First, analysis evaluation units are determined on the basis of the level of details or aggregation required. Second, land use suitability analysis is conducted to eliminate the evaluation units that are not suitable for construction purposes. The remaining evaluation units are passed to the next step for economic feasibility assessment, in which a preliminary maximum building height is determined. Lastly, viewshed analysis is conducted to adjust the development height and to remove any obstruction between the chosen viewpoints and scenic spots. We use Liuzhou City to illustrate the steps and potential of this model.

Our analysis shows that the proposed model can support urban development decision making at the disaggregate and aggregate levels. At the disaggregate level, the DTSMP model is capable of adjusting building height based on the local specifics of small geographic regions. This analysis is performed by selecting the evaluation units of suitable sizes. The example in Table 4 shows the 
effectiveness of this approach. In most Chinese cities, the restrictions on building height are usually crudely determined, with one rule applying to a large region. This "one-height-fits-all" decision model inevitably overlooks the unique local needs and consequently results in sub-optimal solutions. Our DTSMP model enables the optimal development height to be determined objectively at the disaggregate level. Therefore, the results are flexible enough to accommodate the local needs. At the aggregate level, the proposed model is capable of incorporating a large amount of geological, geographical, economic, social, and environmental information at once. More importantly, it can display the results as a complete picture using a 3D sketch, as illustrated in Figure 9. This feature is particularly important and useful for urban planners who always need to view the city as an interlinked entity instead of isolated units. Therefore, the model facilitates urban development decisions at the aggregate levels as well. This viewpoint helps to create communities that are geologically viable, economically feasible, and ecologically sustainable. The proposed framework is a useful tool for the local government to implement the New-type Urbanization Plan while still ensuring urban residents that they could "see the mountains, view the rivers, and remember their past."

\section{Acknowledgments}

This study was supported by the Major Scheme of National Social Science Foundation of China (Grant no. 09\&ZD047) and the Special Research Fund Project for Public Welfare Industry of the Ministry of Land and Resources of China (Grant no. 201511003-2 and 201511010-04). We are grateful to the National Natural Science Foundation of China (Project \#71231005) for the financial support and to the Liuzhou Bureau of Land and Resources and Housing Management for providing us with valuable data. 


\section{References}

1. M. Bendewald, \& Z.Q. Zhai, Using carrying capacity as a baseline for building sustainability assessment, Habitat Int, 37 (2013) 22-32.

2. P. Berke, \& E.J. Kaiser, Urban land use planning, University of Illinois Press, 2006.

3. L. Bertinelli, \& E. Strobl, Urbanisation, urban concentration and economic development, Urban Stud, 44 (2007) 2499-2510.

4. I.D. Bishop, E. Lange, \& A.M. Mahbubul, Estimation of the influence of view components on high-rise apartment pricing using a public survey and GIS modeling, Environ Plann B, 31 (2004) 439-452.

5. I.D. Bishop, J.R. Wherrett, \& D.R. Miller, Using image depth variables as predictors of visual quality, Environ Plann B, 27 (2000) 865-875.

6. S. Burak, E. Dogan, \& C. Gazioglu, Impact of urbanization and tourism on coastal environment, Ocean \& Coastal Management, 47 (2004) 515-527.

7. K.W. Chau, \& S.K. Wong, Externalities of urban renewal: A real option perspective, J Real Estate Financ, 48 (2014) 546-560.

8. M.X. Chen, H. Zhang, W.D. Liu, \& W.Z. Zhang, The global pattern of urbanization and economic growth: evidence from the last three decades, Plos One, 9 (2014).

9. S.S. Chen, Y. Yan, Q. Gao, \& D. Liu, Quantifying circular urban expansion patterns of compact Chinese cities: the case of Yangtze River Delta, China, Environ Plann B, 42 (2015) 279-299.

10. W.Y. Chen, \& F.Z.Y. Hu, Producing nature for public: Land-based urbanization and provision of public green spaces in China, Applied Geography, 58 (2015) 32-40.

11. C.J. Cho, Paying for expansion versus replacement costs: infrastructure provision for efficient urban growth, Annals of Regional Science, 46 (2011) 59-81.

12. F.C. Dai, C.F. Lee, \& X.H. Zhang, GIS-based geo-environmental evaluation for urban land-use planning: a case study, Eng Geol, 61 (2001) 257-271.

13. T. Daniels, \& M. Lapping, Land preservation: An essential ingredient in smart growth, Journal of Planning Literature, 19 (2005) 316-329.

14. L. De Floriani, \& P. Magillo, Algorithms for visibility computation on terrains: a survey, Environ Plann B, 30 (2003) 709-728.

15. L. Defloriani, P. Marzano, \& E. Puppo, Line-of-Sight communication on terrain models, Int J Geogr Inf Syst, 8 (1994) 329-342.

16. X.Z. Deng, J.K. Huang, S. Rozelle, J.P. Zhang, \& Z.H. Li, Impact of urbanization on cultivated land changes in China, Land Use Policy, 45 (2015) 1-7.

17. C. Ding, Managing urban growth for efficiency in infrastructure provision : dynamic capital expansion and urban growth boundary models, Ph.D. Dissertation, University of Illinois at Urbana-Champaign, 1996.

18. C. Ding, The benchmark land price system and urban land use efficiency in China, Chinese Geogr Sci, 11 (2001) 306-314.

19. C. Ding, Urban land use, real estate development ,and urban policy in china, Urban Stud, 10 (2003) 58-63 [in Chinese]. 
20. C. Ding, \& E. Lichtenberg, Land and urban economic growth in China, Journal of Regional Science, 51 (2011) 299-317.

21. M.A. Garcia-Lopez, Urban spatial structure, suburbanization and transportation in Barcelona, Journal of Urban Economics, 72 (2012) 176-190.

22. E. Glaeser, Cities, Productivity, and Quality of Life, Science, 333 (2011) 592-594.

23. J. Gong, W. Chen, Y. Liu, \& J. Wang, The intensity change of urban development land: Implications for the city master plan of Guangzhou, China, Land Use Policy, 40 (2014) 91-100.

24. J.Z. Gong, Y.S. Liu, \& W.L. Chen, Land suitability evaluation for development using a matter-element model: A case study in Zengcheng, Guangzhou, China, Land Use Policy, 29 (2012) 464-472.

25. O. Guzey, Neoliberal urbanism restructuring the city of Ankara: Gated communities as a new life style in a suburban settlement, Cities, 36 (2014) 93-106.

26. H.C. Jenkins-Smith, \& P.A. Sabatier, Evaluating the advocacy coalition framework, Journal of Public Policy, 14 (1994) 175-203.

27. S.D. Joardar, Carrying capacities and standards as bases towards urban infrastructure planning in India: A case of urban water supply and sanitation, Habitat Int, 22 (1998) 327-337.

28. J.B. Jou, \& T. Lee, How do density ceiling controls affect housing prices and urban boundaries?, J Real Estate Financ, 50 (2015) 219-241.

29. A. Koltsova, B. Tuncer, \& G. Schmitt, Visibility analysis for $3 \mathrm{~d}$ urban environments research development and practical application, Ecaade 2013: Computation and Performance, Vol 2, (2013) 375-383.

30. K. Krellenberg, J. Welz, \& S. Reyes-Packe, Urban green areas and their potential for social interaction A case study of a socio-economically mixed neighbourhood in Santiago de Chile, Habitat Int, 44 (2014) 11-21.

31. L. Li, Y. Sato, \& H.H. Zhu, Simulating spatial urban expansion based on a physical process, Landscape Urban Plan, 64 (2003) 67-76.

32. F. Lindberg, \& C.S.B. Grimmond, The influence of vegetation and building morphology on shadow patterns and mean radiant temperatures in urban areas: model development and evaluation, Theoretical and Applied Climatology, 105 (2011) 311-323.

33. H.M. Liu, Comprehensive carrying capacity of the urban agglomeration in the Yangtze River Delta, China, Habitat Int, 36 (2012) 462-470.

34. S. Liu, X.T. Fan, Q.K. Wen, W. Liang, \& Y.F. Wu, Simulated impacts of 3D urban morphology on urban transportation in megacities: case study in Beijing, Int J Digit Earth, 7 (2014) 470-491.

35. M. Llobera, Extending GIS-based visual analysis: the concept of visualscapes, Int J Geogr Inf Sci, 17 (2003) 25-48.

36. J.R. Logan, \& H.L. Molotch, Urban fortunes : the political economy of place, University of California Press, 1987.

37. H.L. Long, Y.Q. Liu, X.G. Hou, T.T. Li, \& Y.R. Li, Effects of land use transitions due to rapid urbanization on ecosystem services: Implications for urban planning in the new developing area of China, Habitat Int, 44 (2014) 536-544. 
38. D. Miller, A method for estimating changes in the visibility of land cover, Landscape Urban Plan, 54 (2001) 91-104.

39. K. Oh, \& W. Lee, Estimating the value of landscape visibility in apartment housing prices, J Archit Plan Res, 19 (2002) 1-11.

40. M. Pacione, The internal structure of cities in the Third World, Geography, 86 (2001) 189-209.

41. J. Qin, C.L. Fang, Y. Wang, G.D. Li, \& S.J. Wang, Evaluation of three-dimensional urban expansion: A case study of Yangzhou City, Jiangsu Province, China, Chinese Geogr Sci, 25 (2015) 224-236.

42. C. Rinner, A geographic visualization approach to multi-criteria evaluation of urban quality of life, Int J Geogr Inf Sci, 21 (2007) 907-919.

43. H.A. Sander, \& S.M. Manson, Heights and locations of artificial structures in viewshed calculation: How close is close enough?, Landscape Urban Plan, 82 (2007) 257-270.

44. B. Shi, \& J. Yang, Scale, distribution, and pattern of mixed land use in central districts: A case study of Nanjing, China, Habitat Int, 46 (2015) 166-177.

45. W.L. Stefanov, M.S. Ramsey, \& P.R. Christensen, Monitoring urban land cover change: An expert system approach to land cover classification of semiarid to arid urban centers, Remote Sensing of Environment, 77 (2001) 173-185.

46. J. Taylor, The China Dream is an Urban Dream: Assessing the CPC's National New-Type Urbanization Plan, J of Chin Polit Sci, (2015) 1-14.

47. G.J. Tian, J.G. Wu, \& Z.F. Yang, Spatial pattern of urban functions in the Beijing metropolitan region, Habitat Int, 34 (2010) 249-255.

48. A. Turner, M. Doxa, D. O'Sullivan, \& A. Penn, From isovists to visibility graphs: a methodology for the analysis of architectural space, Environ Plann B, 28 (2001) 103-121.

49. B.L. Turner II, D. Skole, S. Sanderson, G. Fischer, L. Fresco, \& R. Leemans, Land-Use and Land-Cover Change, Science/Research Plan, in: IGBP Report No. 35/HDP Report No. 7. (1995).

50. United Nations, World Urbanization Prospects, The 2014 Revision, in: World Urbanization Prospects, The 2014 Revision, Publisther, 2014.

51. H.N. van Lier, The role of land use planning in sustainable rural systems, Landscape Urban Plan, 41 (1998) 83-91.

52. R.P. Voith, \& S.M. Wachter, Urban growth and housing affordability: the conflict, Annals of the American Academy of Political and Social Science, 626 (2009) 112-131.

53. F. Wang, G. Wang, D.J. Pan, Y. Liu, L.Z. Yang, \& H.B. Wang, A parallel algorithm for viewshed analysis in three-dimensional Digital Earth, Comput Geosci-Uk, 75 (2015) 57-65.

54. Q. Wang, J.G. Xu, \& W.W. Xu, A GIS approach to the urban land suitability evaluation: a case study of Gaochun in Nanjing, Progress in Geophysics, 20 (2005) 877-880 [in Chinese].

55. Y.G. Wei, C. Huang, P.T.I. Lam, \& Z.Y. Yuan, Sustainable urban development: A review on urban carrying capacity assessment, Habitat Int, 46 (2015) 64-71.

56. S.W. Wong, B.S. Tang, \& B. van Horen, Strategic urban management in China: A case study of Guangzhou Development District, Habitat Int, 30 (2006) 645-667. 
57. E. Wragg, \& R. Lim, Urban visions from Lusaka, Zambia, Habitat Int, 46 (2015) 260-270.

58. J. Xia, F. Xia, \& J. Yan, Method and application of comprehensive evaluation for land use: take Gongyichuang as a case study, Journal of Anhui Agriculture Science, 39 (2011) 20690-20693 [In Chinese].

59. Xinhuanet, Urbanization: allow residents to see the mountains, view the rivers and remember their past (in Chinese).

(http://news.xinhuanet.com/fortune/2013-12/16/c 125862769.htm).

60. Xinhuanet, China unveils landmark urbanization plan (in Chinese). (http://news.xinhuanet.com/english/china/2014-03/16/c_133190495.htm).

61. K. Xu, C.F. Kong, J.F. Li, L.Q. Zhang, \& C.L. Wu, Suitability evaluation of urban construction land based on geo-environmental factors of Hangzhou, China, Comput Geosci-Uk, 37 (2011) 992-1002.

62. J. Yan, F. Xia, \& H.X.H. Bao, Strategic planning framework for land consolidation in China: A top-level design based on SWOT analysis, Habitat Int, 48 (2015) 46-54.

63. X. Yang, \& Y. Li, Development of a three-dimensional urban energy model for predicting and understanding surface temperature distribution, Boundary-Layer Meteorol, 149 (2013) 303-321.

64. Z. Yang, X.C. Zhu, \& D.R. Moodie, Optimization of land use in a new urban district, J Urban Plan Dev, 141 (2015).

65. H. Yoshida, \& M. Omae, An approach for analysis of urban morphology: methods to derive morphological properties of city blocks by using an urban landscape model and their interpretations, Computers, Environment and Urban Systems, 29 (2005) 223-247.

66. B.L. Yu, H.X. Liu, J.P. Wu, Y.J. Hu, \& L. Zhang, Automated derivation of urban building density information using airborne LiDAR data and object-based method, Landscape Urban Plan, 98 (2010) 210-219.

67. J. Zacharias, Preferences for view corridors through the urban environment, Landscape Urban Plan, 43 (1999) 217-225.

68. X.R. Zhang, C.L. Fang, Z.B. Wang, \& H.T. Ma, Urban construction land suitability evaluation based on improved multi-criteria evaluation based on GIS (MCE-GIS): Case of New Hefei City, China, Chinese Geogr Sci, 23 (2013) 740-753. 